\begin{tabular}{|c|c|c|c|c|c|c|}
\hline \multirow{4}{*}{ Impact Factor: } & ISRA (India) & $=3.117$ & SIS (USA) & $=0.912$ & ICV (Poland) & $=6.630$ \\
\hline & ISI (Dubai, UAE & $=0.829$ & РИНЦ (Russia & $=0.156$ & PIF (India) & $=1.940$ \\
\hline & GIF (Australia) & $=0.564$ & ESJI (KZ) & $=8.716$ & IBI (India) & $=4.260$ \\
\hline & JIF & $=1.500$ & SJIF (Morocco & $=\mathbf{5 . 6 6 7}$ & OAJI (USA) & $=0.350$ \\
\hline
\end{tabular}

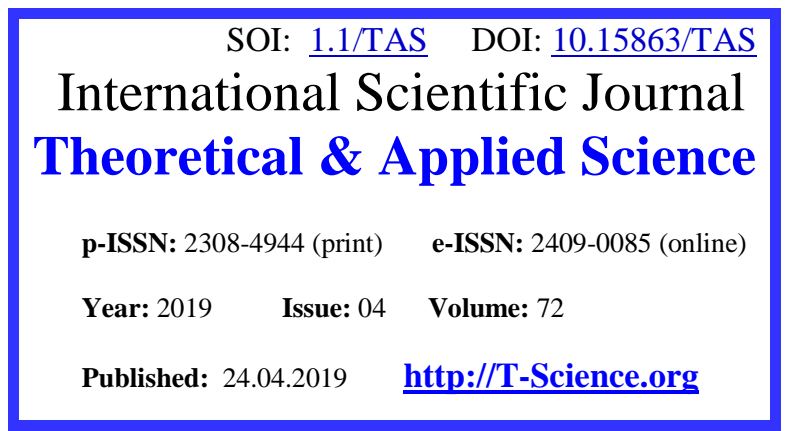

SECTION 32. Jurisprudence.
QR - Issue

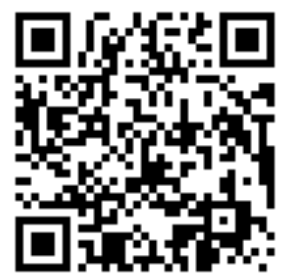

QR - Article

\title{
SOFTWARE DATABASES BASED ON CRIMINOLOGICAL- \\ CRIMINALISTIC CHARACTERISTICS OF CRIMES MADE AGAINST LIFE AND HEALTH OF HUMAN
}

Bakitbek Eshimbekovich Kapalov Adjunct of Police Academy in Bishkek Lieutenant colonel of militia LIFE AND HEALTH OF HUMAN

Abstract: forensic scientists have long argued that it is necessary to create a form of accounting for certain types of crimes on the basis of the criminalistic characteristic of a crime. Back in the 1980s. it was proposed to develop a special card to describe the elements of the forensic characteristics of the crimes already investigated. Information about the links between the components of individual forensic characteristics of solved crimes can be used in the construction of versions and, as such, acquires the importance of the most important section of forensic accounting.

Key words: software; database; forensic characterization of homicides; criminological characteristics of murder; forensic accounting; the fight against crime.

Language: Russian

Citation: Kapalov, B. E. (2019). Software databases based on criminological-criminalistic characteristics of crimes made against life and health of human. ISJ Theoretical \& Applied Science, 04 (72), 328-332.

Soi: http://s-o-i.org/1.1/TAS-04-72-39 Doi: crossef https://dx.doi.org/10.15863/TAS.2019.04.72.39

\section{ПРОГРАММНОЕ ОБЕСПЕЧЕНИЕ БАЗЫ ДАННЫХ НА ОСНОВЕ \\ КРИМИНОЛОГО-КРИМИНАЛИСТИЧЕСКОЙ ХАРАКТЕРИСТИКИ ПРЕСТУПЛЕНИЙ, СОВЕРШАЕМЫХ ПРОТИВ ЖИЗНИ И ЗДОРОВЬЯ ЧЕЛОВЕКА}

Аннотация: ученые-криминалисть давно доказывают необходимость создания на основе криминалистической характеристики преступления формы учета отдельных видов преступлений. Еще в 1980-е г2. предлагалось разработать специальную карточку для описания элементов криминалистических характеристик уже расследованных преступлений. Информация о связях между компонентами индивидуальных криминалистических характеристик раскрытых преступлений может использоваться при построении версий и в таком качестве приобретает значение важнейшего раздела криминалистических учетов.

Ключевые слова: программное обеспечение; база данных; криминалистическая характеристика убийств; криминологическая характеристика убийств; криминалистические учеты; борьба с преступностью.

\section{Актуальность.}

Сегодня как никогда велика потребность в криминалистическом мониторинге, т. е. системном криминалистическом наблюдении и изучении преступной среды, что позволит создать широкую эмпирическую базу для различных исследований, в том числе для разработки новых эффективных методик расследования отдельных категорий преступлений.

\section{Методология.}

В настоящее время, для обеспечения быстрой обработки криминалистической характеристики преступлений при расследовании применяются автоматизированные процессы, технологии которых основаны на использовании электронных баз данных, а также на современных информационно-коммуникационных системах.

Например, в США на протяжении 25 лет успешно функционирует программа по предотвращению насильственных преступлений 


\begin{tabular}{|c|c|c|c|c|c|c|}
\hline \multirow{4}{*}{ Impact Factor: } & ISRA (India) & $=3.117$ & SIS (USA) & $=0.912$ & ICV (Poland) & $=6.630$ \\
\hline & ISI (Dubai, UAE & $=0.829$ & РИНЦ (Russia) & $=0.156$ & PIF (India) & $=1.940$ \\
\hline & GIF (Australia) & $=0.564$ & ESJI (KZ) & $=8.716$ & IBI (India) & $=4.260$ \\
\hline & JIF & $=1.500$ & SJIF (Morocco & $=5.667$ & OAJI (USA) & $=0.350$ \\
\hline
\end{tabular}

(VICAP), которая представляет собой базу данных по установлению взаимосвязей между характерными элементами насильственных преступлений. По специальной программе в нее заносятся сведения о всех совершаемых в США тяжких насильственных преступлениях, как раскрытых, так и нераскрытых (соответственно около 15 тыс. и 5 тыс. ежегодно) [1].

Реляционная база данных - это набор нормализованных отношений, которые различаются по именам. Ключевым понятием здесь является понятие отношения, которое в английском языке звучит как relation. Программное обеспечение, которое управляет доступом к базе данных, принято называть системой управления базой данных (далее СУБД).

Предшественниками реляционных СУБД были ручная картотека и файловая система, недостатками которых являются разделение, изоляция и дублирование данных, а также зависимость от них. В этом отношении систему следственной деятельности также можно сравнить с файловой системой, но более - c ручной картотекой, ведь опыт отдельного следователя никак не связан с опытом других и сразу же утрачивается, как только следователь уходит из системы. Реляционная модель данных, несмотря на кажущуюся простоту своей логической структуры, базируется на серьезном теоретическом фундаменте что позволяет преодолеть указанные недостатки, прежде всего за счет использования механизма манипулирования данными или языка запросов (Structured Query Language - SQL), который обеспечивает выборку и обновление данных.

База данных спроектирована нами на основе криминалистической характеристики преступлений (далее - КХП). С учетом этого здесь уместно сделать несколько замечаний.

Несмотря на обилие работ о КХП, единого мнения о ее сущности, видах и практической значимости в криминалистике не сложилось, хотя само это понятие было введено в правовое поле еще в 1960-х гг. [2] как справедливо пишет В. П. Бахин, «по теории криминалистической характеристики преступлений имеется множество литературы, но это лишь подходы и основа для разработки рабочего инструментария расследования. А вот в этом направлении пока практически ничего не сделано» [3, с. 180]. Более того, высказывалась и мысль, в частности Р. С. Белкиным, о несостоятельности «фантомности» данной категории [4, с. 233].

Но хотя большинство авторов все же признают теоретическую и практическую значимость КХП [5, с. 24], единства мнений относительно самой сути этой категории у них не сложилось. Так, одни из них полагают, что КХП есть система данных о преступлении, способствующая раскрытию и расследованию преступления [6, с. 144], другие же считают, что КХП представляет собой вероятностную информационную модель типичных признаков определенной группы преступлений [7, с. 5].

В то же время в литературе выделяют два, три и более видов КХП. Например, Г. А. Густов анализирует общую криминалистическую характеристику

криминалистическую преступления; характеристику конкретного преступления [8, с. 46]. И. Ф. Крылов также полагает, что «... криминалистическая характеристика может (и должна) быть трех степеней (уровней): а) общая характеристика всех видов преступлений; б) характеристика группы или вида преступлений; в) характеристика конкретного преступления. И. Ф. Пантелеева же считает, что «существует криминалистическая характеристика вида (группы) преступлений, а также отдельного, конкретного преступления, но не преступления вообще» [9, с. 26].

Диаметрально противоположной позиции придерживаются Р. С. Белкин, И. Е. Быховский, А. В. Дулов, категорически отрицая существование криминалистической характеристики конкретного преступления. Они пишут: «Поскольку речь идет о научной абстракции, научном понятии, нет и не может быть криминалистической характеристики конкретного преступления» [10, с. 57].

Причину такой резкой поляризации подходов к определению сущности КХП еще в 70-х гг. прошлого столетия объяснил Л. Я. Драпкин: «Несовпадение взглядов различных авторов, неточности предлагаемых формулировок отражают прежде всего исключительную сложность и многогранность исследуемого объекта, многообразие связей между его структурными элементами» [11, с. 12].

Не вдаваясь в указанную дискуссию, отметим, что мы придерживаемся определения, данного Е. П. Ищенко, который считает, что криминалистическая характеристика убийств это «система взаимосвязанных обобщенных данных о наиболее типичных признаках, проявляющихся в способе и механизме убийства, обстановке его совершения, личности преступника и других сторонах этого преступления, сведения о которых важны для практического решения задач расследования» $[12$, c. 466].

Кроме того, мы согласны с необходимостью составления криминалистических характеристик конкретных преступлений. Как правильно отметил В. В. Бирюков, нельзя создать криминалистическую характеристику вида или группы преступлений без кропотливого, детального анализа расследования каждого конкретного преступления - сложнейших систем, на которые она опирается [13, с. 33-35]. 


\begin{tabular}{|c|c|c|c|c|c|c|}
\hline \multirow{4}{*}{ Impact Factor: } & ISRA (India) & $=3.117$ & SIS (USA) & $=0.912$ & ICV (Poland) & $=6.630$ \\
\hline & ISI (Dubai, UAE & $=0.829$ & РИНЦ (Russia & $=0.156$ & PIF (India) & $=1.940$ \\
\hline & GIF (Australia) & $=0.564$ & ESJI (KZ) & $=8.716$ & IBI (India) & $=4.260$ \\
\hline & JIF & $=1.500$ & SJIF (Morocco & $=5.667$ & OAJI (USA) & $=0.350$ \\
\hline
\end{tabular}

На наш взгляд, чтобы обеспечить выполнение основной прикладной функции КХП - раскрытия конкретных преступлений - она должна быть представлена в виде электронной базы данных, позволяющей трансформировать каждый ее элемент в активное поисковое поле, связанное со структурой КХП в целом. Это позволит извлекать и актуализировать опыт расследования преступлений с учетом особенностей того района, населенного пункта и региона, где ведется база данных, а в итоге выделить и использовать как криминалистическую характеристику конкретного преступления и отдельных ее элементов, аналогичных или схожих с вновь совершенным убийством, так и видовую его криминалистическую характеристику в целом. То есть применение базы данных позволяет использовать все виды КХП: и конкретного преступления, и вида преступлений.

П. Ю. Фесик справедливо, на наш взгляд, считает, что в базе данных КХП предстает на трех уровнях: элементы КХП, из признаки, значения (градации) признаков [14, с. 39-44]. Действительно, каждый уровень КХП детализирует ее содержание, переходя от общего к частному, что неизбежно при конструировании любой базы данных, поскольку каждая запись (в терминологии баз данных - атрибут) в еe структуре должна содержать значения одного признака, чтобы имелась возможность сравнивать их между собой. Например, признак обстановки «характеристика места происшествия» конкретизируется в значениях город, квартира, улица и т. п.

На наш взгляд, важно, чтобы список значений не был фиксированным, мог свободно дополняться развивая и дополняя базу содержание КХП конкретными значениями, касающимися поведения преступника в пред- и посткриминальных ситуациях, а также в ходе самого преступления, по которым возможно установить его личность [15, с. 16].

Здесь мы используем подход, заключающийся в переходе от типичных версий к накоплению сведений о реальном поведении преступников до, в процессе и после совершения убийств.

Например, Г. А. Кокуриным сформулированы типичные версии о предполагаемых объектах - носителях криминалистической информации, выдвигаемые в поисковых ситуациях проблемного характера:

1) Преступник ранее совершал аналогичные преступления, изучение дел о которых позволит получить дополнительную информацию поискового характера;

2) Преступник появится в данном районе, в том числе на месте происшествия;
3) В районе совершения преступлений могут находиться следы и объекты-носители криминалистической информации;

4) Преступник может совершить новое преступление, в том числе в определенных микрорайонах;

5) В районе, где совершались преступления, вероятно можно установить источники информации о латентных преступлениях, совершенных тем же неизвестным преступником;

6) Преступник проживает в данном районе, местности;

7) Преступник собирается сбыть похищенное, в том числе через известных сбытчиков;

8) Преступник собирается покинуть этот район или уже выехал из него;

9) Преступник относится к группе гастролеров и появится в городе (населенном пункте) в определенные периоды (дни недели, месяца и т. д.) [16, с. 101-102].

Мы считаем, что в базе данных необходимо конкретизировать каждую такую версию в виде элементов, содержащих сведения о том, например, в какое время и на какие аналогичные преступления (иные правонарушения) совершало лицо до и после убийства, в какое время преступник появлялся в районе или непосредственно на месте происшествия и т. д. (ниже, при описании элементов разработанной нами базы данных мы привели содержание таких элементов поведения преступника).

Тот же подход был применен при формировании всего блока пред- и посткриминальных ситуаций, чтобы на основе этих сведений можно было не только выдвинуть типичную версию, но и разработать алгоритмы по получению искомой информации о личности преступника с указанием, когда, где и как ее возможно получить.

Рассматривая возможность программного обеспечения базы данных на основе криминалистической характеристики убийств и непосредственно связанного с этим элементом личностью преступника, нельзя упомянуть о криминологической характеристики лиц, совершающих убийство.

Так по мнению Ю. М. Антоняном, указанные преступники плохо отличают социальную приспособленность, общее неудовлетворенное оценивание своего положения в социуме. Ярко выраженная импульсивность, проявляемая в снижении самоконтроля над своим поведением, необдуманными поступками, эмоциональной незрелости, и инфантилизме. Нравственные и правовые догмы не могут оказать на их поведение существенного влияния. Данная категория людей обычно или не понимает, чего от них добивается социум, либо понимает, но в силу не желания эти 


\begin{tabular}{|c|c|c|c|c|c|c|}
\hline \multirow{4}{*}{ Impact Factor: } & ISRA (India) & $=3.117$ & SIS (USA) & $=0.912$ & ICV (Poland) & $=6.630$ \\
\hline & ISI (Dubai, UAE & $=0.829$ & РИНЦ (Russia & $=\mathbf{0 . 1 5 6}$ & PIF (India) & $=1.940$ \\
\hline & GIF (Australia) & $=0.564$ & ESJI (KZ) & $=8.716$ & IBI (India) & $=4.260$ \\
\hline & JIF & $=1.500$ & SJIF (Morocco & $=5.667$ & OAJI (USA) & $=0.350$ \\
\hline
\end{tabular}

требования не выполняют. В силу нарушения или деформации нормативного контроля, они способны оценивать социальную ситуацию не основываясь на нравственных и правовых требованиях, а исходя из субъективных переживаний и обид.

Простыми словами, на лицо стойкое деформирование социальной адаптации. Им характерны также нарушения в сфере общения:

- они неспособны устанавливать контакты с окружающими людьми;

- они не умеют и не хотят понимать точки зрения других;

- не желают смотреть на себя со стороны.

Это в свою очередь снижает возможность адекватной ориентации, продуцирует возникновение аффективно насыщенных идей, связанных с представление о враждебности со стороны окружающих людей и общества в целом. Bce вместе взятое формирует такие черты, как погруженность в себя, замкнутость, отгороженность, с одной стороны, и агрессивность, подозрительность - с другой. В результате правильная оценка ситуации еще более затрудняется, поскольку поведением управляют аффективные установки, а поступки окружающих рассматриваются как опасные, угрожающие личности, что проводит к противоправным способом выхода из сложившейся ситуации. Психологический профиль насильников характеризуется такими чертами, как склонность к доминированию и преодолению препятствий. У них самая низкая чувствительность в межличностных контактах (черствость), и в наименьшей степени выражены склонность к самоанализу и способность поставить себя на место другого. Интеллектуальный контроль поведения такой же низкий, как и у корыстнонасильственных преступников. Им присущи также импульсивность, ригидность, социальная отчужденность, нарушение адаптации [17, с. 45].

\section{Вывод:}

Таким образом, очевидно, что потенциал использования базы данных намного шире, чем составление вероятного портрета преступника в программе «ФОРВЕР». На наш взгляд, в базе должны аккумулироваться в единую структуру и КХП, и характеристики деятельности следствия, и раскрытые, и нераскрытые преступления, чтобы сформировать не только вероятный портрет преступника (это важный, но лишь первый шаг в установлении убийцы), но и конкретные сведения о его вероятном местонахождении и поведении, на основе которых можно составить систему алгоритмов (программу) по установлению его личности.

В перспективе в эту же базу могут войти данные иных криминалистических учетов, прежде всего следов рук, ДНК и др. На наш взгляд, именно по этому пути - дальнейшей интеграции в единую систему баз данных криминалистически значимой информации - должна пойти практика борьбы с преступностью.

\section{References:}

1. Michael, D. (2011). Lyman Criminal Investigation: The Art and the Science? Sixth Edition. (p.308). New Jersey.

2. (1967). Ponyatie KHP vvedeno v kriminalistiku v 1960-h gg. Sm.: Kolesnichenko A. N. Nauchnyie i pravovyie osnovyi rassledovaniya otdelnyih vidov prestupleniy: avtoref. Dis. ... dra yurid. nauk. (p.10). Harkov.

3. Bahin, V. P. (2002). Kriminalistika. Problemyi $i$ mneniya (1962-2002). (p.180). Kiev.

4. Belkin, R. S. (2001). Kriminalistika: problemyi segodnyashnego dnya. Zlobodnevnyie voprosyi rassiyskoy kriminalistiki. (p.233). Moscow.

5. Ahmedshin, R. L. (2005). Kriminalisticheskaya harakteristika lichnosti prestupnika. (p.24). Tomsk.
6. Matusovskiy, G. A. (1998). Kriminalistichna harakteristika zlochiniv. Kriminalistika. (p.144). Harkiv.

7. Bahin, V. P., \& Gora, I. V. (1998). «Kontrkriminalistika» ili novyie zadachi kriminalistiki. Aktulni problemi derzhavi ta prava. (p.5). Odessa, Vip 5.

8. Gustov, G. A. (1984). Ponyatie $i$ vidyi kriminalisticheskoy harakteristiki prestupleniy. Kriminalisticheskaya harakteristika prestupleniy. (p.46). Moscow.

9. Panteleeva, I. F., \& Selivanova, N. A. (1993). Kriminalistika: ucheb. (p.26). Moscow.

10. Belkin, R., Byihovskiy, I., \& Dulov, A. (1987). Modnoe uvlechenie ili novoe slovo $\mathrm{v}$ nauke? (Esche raz o kriminalisticheskoy harakteristiki prestupleniya). Sots. zakonnost, \# 9, p. 57. 


\begin{tabular}{|c|c|c|c|c|c|c|}
\hline \multirow{4}{*}{ Impact Factor: } & ISRA (India) & $=3.117$ & SIS (USA) & $=0.912$ & ICV (Poland) & $=6.630$ \\
\hline & ISI (Dubai, UAE & $=0.829$ & РИНЦ (Russia & $=\mathbf{0 . 1 5 6}$ & PIF (India) & $=1.940$ \\
\hline & GIF (Australia) & $=0.564$ & ESJI (KZ) & $=8.716$ & IBI (India) & $=4.260$ \\
\hline & JIF & $=1.500$ & SJIF (Morocco & $=5.667$ & OAJI (USA) & $=0.350$ \\
\hline
\end{tabular}

11. Drapkin, L. Y. (1978). Predmet dokazyivaniya $i$ kriminalisticheskie harakteristiki prestupleniy. Kriminalisticheskie harakteristiki $\mathrm{v}$ metodiki rassledovaniya prestupleniy: sb. nauch. tr. Sverdlovsk, Vyip. 69, p. 12.

12. (n.d.). Kriminalistika: ucheb. / pod red. E. P. Ischenko (Eds.). (p. 466). Moscow.

13. Biryukov, V. V., \& Biryukova, T. P. (2016). Kriminalisticheskaya harakteristika konkretnyih prestupleniy: znachenie i perspektivyi ispolzovaniya $\mathrm{v}$ teorii i v praktike rassledovaniy. Ros. pravo: obrazovanie, praktika, nauka, \# 3, pp.33-35.
14. Fesik, P. Y. (n.d.). Ispolzovanie kriminalisticheskoy harakteristiki $v$ raskryitii ubiystv. pp. 39-44.

15. Kruchinina, N. V. (2003). Osnovyi kriminalisticheskogo ucheniya o proverke dostovernosti ugolovno-relevantnoy informatsii: avtoref. Dis. ... d-ra yurid. nauk. (p.16). Moscow.

16. Kokurin, G. A. (2001). Teoreticheskie $i$ prakticheskie osnovyi deyatelnosti v protsesse raskryitiya i rassledovaniya prestupleniy: dis. ... d-ra yurid. nauk. (pp.101-102). Ekaterinburg.

17. Antonyan, Y. M. (1997). Psihologiya ubiystva. (p.45). Moscow. 